\title{
Guidelines for Designing Augmented Reality Games
}

\author{
Richard Wetzel, Rod McCall, Anne-Kathrin Braun, Wolfgang Broll \\ Collaborative Virtual and Augmented Environments \\ Fraunhofer FIT \\ Schloss Birlinghoven \\ DE-53754 Sankt Augustin - Germany \\ $+49-2241-142148$ \\ \{richard.wetzel, rod.mccall, anne.braun, wolfgang.broll\}@fit.fraunhofer.de
}

\begin{abstract}
The growing popularity of augmented reality (AR) games in both a research and more recently commercial context has led for a need to take a closer look at design related issues which impact on player experience. While issues relating to this area have been considered, to date most of the emphasis has been on the technology aspects. Furthermore it is almost always assumed that the augmented reality element in itself will provide a sufficient experience for the player. This has led to a need to evaluate what makes a successful augmented reality game.

In this paper we present a set of design guidelines which are drawn from experiences of three mixed reality games. The guidelines provide specific guidance on relationships between real and virtual space, social interaction, use of AR technologies, maintaining consistent themes and implicitly address higher level aspects such as presence within a particular augmented reality place.
\end{abstract}

\section{Categories and Subject Descriptors}

H.5.1 [Multimedia Information Systems]: Artificial, augmented,

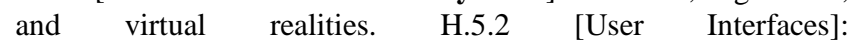
Evaluation/methodology - Graphical user interfaces (GUI) - Input devices and strategies. I.3.1 [Hardware Architecture]: Input devices. I.3.6 [Computer Graphics]: Methodology and Techniques - Interaction Techniques. K.8.0 [Personal Computing]: General Games.

\section{General Terms}

Design, Human Factors, Languages.

\section{Keywords}

Augmented Reality, Augmented Reality Games, Game Design, Game Design Guidelines

\section{INTRODUCTION}

Augmented Reality (AR) takes the real world and enhances it by adding virtual objects, thus giving the user the illusion of a richer environment and enabling designers to create a coherent, interactive experience [1] [17]. Furthermore, advances in tracking technologies and general computing power make it possible to play AR games not only in your home, but in the city, in the

Permission to make digital or hard copies of all or part of this work for personal or classroom use is granted without fee provided that copies are not made or distributed for profit or commercial advantage and that copies bear this notice and the full citation on the first page. To copy otherwise, or republish, to post on servers or to redistribute to lists, requires prior specific permission and/or a fee.

FuturePlay 2008, November 3-5, 2008, Toronto, Ontario, Canada.

Copvright 2008 ACM 978-1-60558-218-4 ..\$5.00. natural environment and even using your PDA or cell phone. Combined with the possibility to place game objects and characters literally everywhere without being restricted to your desktop computer sparks new ideas and has created some truly unique and engaging gaming experiences.

However, game design considerations that explicitly cater for the affordances of Augmented Reality games have often been considered as of secondary importance when compared to the technocal aspects. Furthermore, the technological aspect arguably tend to overwhelm first-time players, who often respond to the novelty of the situation more than the underlying gaming experience. This problem makes it difficult to evaluate such games.

As a result of the issues mentioned before the focus of this paper is the game design aspects of AR games. What constitutes a truly "good" Augmented Reality game? What kind of design mistakes are easy to make? How is AR best utilized in a game? To answer these questions we start with a short overview of games developed within industrial and research contexts. In section 3 two sample AR games we developed are described (Interference and TimeWarp) as well as the recently released Sony PlayStation AR game The Eye of Judgment. Based on experiences with these games, we present our findings in section 4 in the form of game design guidelines. This is followed by a short discussion in section 5 and finally a conclusion in section 6 .

\section{Related Work}

When playing an AR game, the player needs to be equipped with appropriate hardware [6]. In addition to a computer, this hardware often involves technologies for detecting the position and orientation of the player or other game entities. Some games also require communication mechanisms that enable team play or data sharing.

Two types of computer system are commonly used for AR games. On the one hand there are mobile handheld-based systems, running on a PDA or a smart phone. An example for such a system is ARSoccer [20]. In this smart phone-based game a player has to shoot a penalty using a virtual ball into a virtual goal. Using computer vision, the camera in the phone detects the player's foot. Another example is AR Tennis [11]. This is a multiuser virtual tennis game. In this game the devices are connected via Bluetooth and the tracking is realized with fiducial markers. The Invisible Train [24] is also a multi user marker-based game. The goal of the game is to steer a virtual train on a real wooden railroad track. In 2006, Capture the Flag [8] was developed. In this game a team has to catch the opponent's flag. The flag is represented as a Bluetooth device with a touch sensor. This device is connected to the player's phone via Bluetooth. 
The other system used for such games are AR systems consisting of a backpacked laptop and a head-mounted display (HMD). A example of such a game using both, handheld-based devices and AR systems is Epidemic Menace [14]. This game, developed in 2007, take place indoor as well as outdoor. It uses an AR system for augmentation and a PDA for GPS navigation. Smart phones are used to communicate between the indoor team and the outdoor players. The predecessor game of Epidemic Menace is NetAttack [6], developed in 2004. NetAttack is also played indoors and outdoors but uses only a mobile AR system. Besides GPS, the tracking values are stabilized using ARToolKit tracking [13]. The synchronization of the game in Epidemic Menace as well as in NetAttack is provided by a Wifi connection. A similar game to NetAttack is ARQuake [19]. ARQuake is the AR version of the well-known desktop game Quake. Developed in 2002, it was one of the first AR games. Another adaption of a video game is Human Pacman [9]. The game contains the same story as the nonAR game Pacman. Players, equipped with a mobile AR system, have to collect all the cookies before being caught by other players.

In addition to games developed within research groups, there exists a small amount of commercially available AR games. The first was Eye Toy ${ }^{\circledR}{ }^{1}$. Released in 2003 , a special USB camera for the Playstation ${ }^{\circledR}$ console enables the user to play via the TV screen. Using computer vision-based techniques, Eye Toy supports games such as dancing, boxing and other sport-like games, where the player interacts using real physical movements. In 2007, another AR game was released for Playstation3 ${ }^{\circledR}$. In The Eye of Judgment ${ }^{2}$, the external USB camera attached to the game console detects action cards and augments virtual objects on the screen. This game will be described in detail in section 3 .

\section{Comparision of current AR games}

In this section we will compare three different AR games. The games Interference and TimeWarp were developed by us, while The Eye of Judgment is a commercial product published for the Sony PlayStation 3. Each of the games presented later in this section utilises a different range of characteristics, technologies and interaction techniques and a summary is presented in table 1. Together the games offer a diverse view of current developments and build a solid foundation for our analysis in section 4 .
Table 1. Comparison of game characteristics.

\begin{tabular}{|c|c|c|c|}
\hline Characteristic & Interference & TimeWarp & $\begin{array}{c}\text { The Eye of } \\
\text { Judgment }\end{array}$ \\
\hline $\begin{array}{c}\text { Augmented } \\
\text { Reality }\end{array}$ & Magic Lens & $\begin{array}{c}\text { Optical see- } \\
\text { through } \\
\text { HMD }\end{array}$ & Desktop AR \\
\hline $\begin{array}{c}\text { Basic } \\
\text { Hardware }\end{array}$ & UMPC & Laptop & PlayStation 3 \\
\hline Tracking & $\begin{array}{c}\text { Webcam, } \\
\text { marker based }\end{array}$ & $\begin{array}{c}\text { GPS, Inertial } \\
\text { sensor }\end{array}$ & $\begin{array}{c}\text { Webcam, } \\
\text { marker based }\end{array}$ \\
\hline Playing Area & City streets & City streets & table \\
\hline $\begin{array}{c}\text { Interaction } \\
\text { devices }\end{array}$ & none & mouse & cards \\
\hline $\begin{array}{c}\text { Interaction } \\
\text { techniques }\end{array}$ & Looking & $\begin{array}{c}\text { Looking, } \\
\text { Proximity, } \\
\text { Selection, } \\
\text { Steering }\end{array}$ & Playing cards \\
\hline
\end{tabular}

\subsection{Interference}

„Interference“ is a crossmedia game that uses a variety of different devices and playing forms to create an engaging pervasive gaming experience. It was designed by the Interactive Institute [4] and developed by them in cooperation with Fraunhofer FIT. So far Interference has been staged four times in Kista, Sweden, and three times in Düsseldorf, Germany. The game is played on the streets of the city centre a short time before sunset and lasts for about 4 to 5 hours.

\subsubsection{Game play}

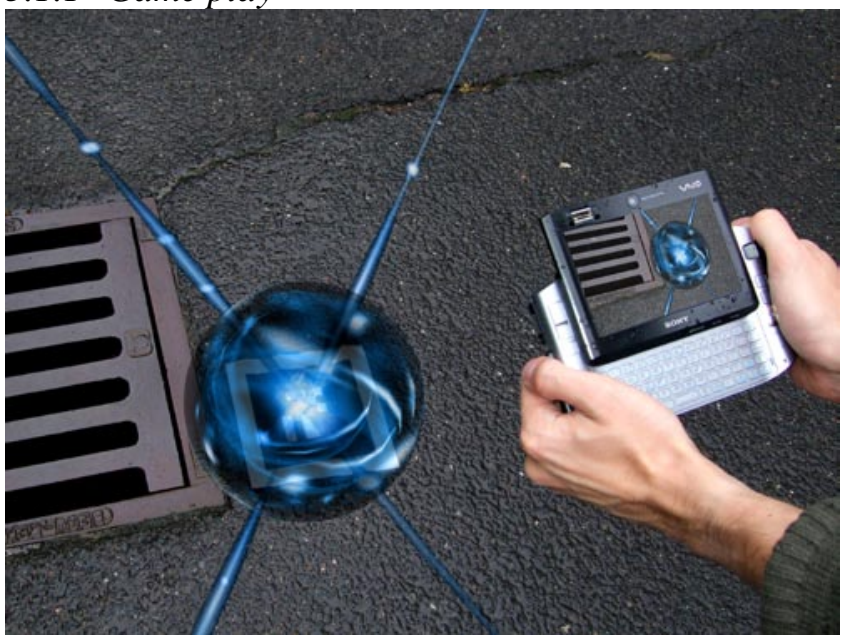

Figure 1: A player of Interference investigating a network node with his UMPC.

In the description of the game play we will focus on the Augmented Reality part and only briefly cover the other. In the game, a group of six players assume of the roles of telecommunication technicians. They are asked by their boss (played by an actor) to investigate strange breakdowns in the network. Wearing overalls and equipped with some gadgets, the players seek out to find these disturbances. The first one is easily found: a pulsating blue sphere serving as a node in the network. The players also recognize two energy lines going into different directions as seen in Fig. 1.. The players can now follow these

\footnotetext{
${ }^{1}$ http://www.eyetoy.com/

${ }^{2}$ http://www.eyeofjudgment.com/
} 
lines only to find other network nodes and more energy lines thus enabling them to scout out the complete network. Suddenly, the players stumble about very different nodes, they are bright orange and disturbed by frequent flashes of lightning.

This is the moment where the story of the game as well as the style changes. Before, everything was rather technical and the game seemed more like a puzzle / treasure hunt, the story now becomes deeper and more mysterious. The players encounter other characters (also played by actors) and receive mysterious phone calls and videos from the past on their cell phones. Ultimately the players have to repair the orange nodes by playing a certain melody on a magic flute they get from one of the nonplayer characters. They then encounter two of the characters in a dramatic scene on a rooftop and have to make a meaningful final decision with political undertones that will shape the future of the world.

\subsubsection{Technology}

The Augmented Reality part of Interference was developed with the "Magic Lens Box", an authoring system for quick and easy development of Augmented Reality games [25]. The "Magic Lens Box" is based on the MoRgAN AR/VR Framework [18].

For discovering the network, the players are equipped with an Ultra-mobile PC (UMPC) which makes use of the "magic lens" metaphor [5]: The video stream of a webcam situated at the back of the UMPC is shown on the display and enriched with virtual objects. This gives the impression of having a see-through display in your hands.

For tracking purposes the system employs the computer-vision based ARToolkitPlus library [23] which is an extension of the original ARToolkit [13] and is specifically designed for mobile devices. Before the game starts, the game masters distribute printed markers throughout the city at pre-defined locations. When the players find one of these markers, they aim the UMPC at the marker and a 3D representation appears. The cell phones used to receive messages and videos work by GPS positioning. Whenever the players enter a certain GPS area, the game server automatically triggers messages and videos. A simple sound sensor connected to one of the phones via Bluetooth reacts to playing the magical flute and sends the information to the game server that in turn evaluates the notes. Afterwards this is relayed to the UMPC and after a successful attempt at repairing the nodes the $3 \mathrm{~d}$ representation changes from the broken orange node to a healthy blue one. To help them with their task of scouting out the complete network the players are equipped with a large map of the area, a drawing board, rulers and different pens, as well as flashlights as the main part of the game is played after dark.

\subsubsection{Evaluation}

In autumn 2007, Interference was tested within several user studies. Different kinds of approaches were used. On the one hand we applied unassisted user trials and on the other hand we conducted assisted student projects.

For the student projects, we had three different user groups. The first group was a a high school class. This group consisting of teenagers aged 15 - 17 represents the most active game consumer segment. The second was a group of larp (live role-playing ${ }^{3}$ ) hobbyists. This group, aged $20-25$, represents the semiprofessional pervasive game organizers. And the third group consisted of game design students at university level. This group, aged 19-24, represented semi-professional game designers and implementers. We observed the players during the game and interviewed them afterwards.

The unassisted user trials were carried out over a period of three months total. They were also asked to document their experiments through taking pictures or video, and to keep some kind of notes in diary form of their experiments. After the trials, we met with each group and discussed their experiences in the form of a semistructured group interview. They were also asked to fill in a survey questionnaire which was used to profile the participants in terms of their age and gender profile, education, gaming interests and previous experience of pervasive games

\subsection{TimeWarp}

TimeWarp [12] is an outdoor augmented reality game played in the city of Cologne, Germany. In TimeWarp, the player is able to explore the city's history using AR. The development of the game is still ongoing. The first test runs were conducted during summer 2007, and another study is currently ongoing.

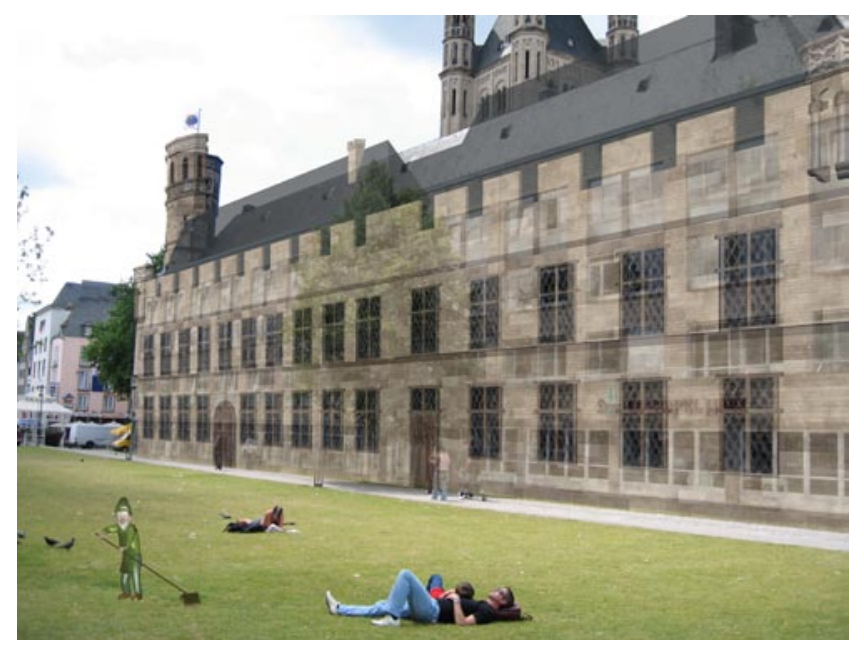

Figure 2 Augmentation with the medieval representation of the trading hall.

\subsubsection{Game play}

The story of the game based on a traditional German legend of the so called "Heinzelmännchen" of Cologne. These were small elves who helped the citizens secretly during the night until one day they suddenly disappeared. In the game a rumor is spread that these elves are still in town but stuck in different time periods. The goal is to find the elves by the means of time travel and to bring them back. To free the Heinzelmännchen, the player has to

\footnotetext{
${ }^{3}$ Live role-players are a good user category for pervasive games (Stenros et al 2007), as they are well acquainted with playing games in the real world.
} 
solve several tasks. These tasks are related to the history of Cologne.

Through the addition of visual and acoustic augmentations, a sense of spatial and temporal presence is created. For example, the original medieval representation of the important trading hall (see Figure 2), which was destroyed during the war, and reconstructed (but was modified), can be experienced. The game play is such that the player can experience the city in the Roman, New Age, Present and future time periods.

\subsubsection{Technology}

The player is equipped with mobile AR system consisting of a head-mounted display (HMD), which is covered by a black foil to protect of the bright sun (see Figure 3). The laptop is packed to the back pocket of a vest. The inertial sensor for orientation tracking is attached to the HMD. For position tracking, a GPS sensor is used. In addition to a headset for the sound and a mouse for interaction, the player is also equipped with a handheld-based device. The PDA is used to provide the player with information about the game, help and current game status. An interactive map shows the current position of the player.

TimeWarp is based on the Interference game and on the MoRGAN AR/VR Framework [18]. We implemented three core interaction controls. The first control uses physical proximity; here the system reacts to the player's physical proximity to an object or location. We distinguish between three distances: outside, near or directly at the game location. The second control is the focusaction-control. Focus is controlled by a view pointer, dveloped using an orientation sensor attached to the HMD. The action is triggered by pressing a mouse button. The third control is the placing control. Using a gyroscopic mouse moving in midair, an item can be placed. This interaction control was inspired by the Wii remote controller.

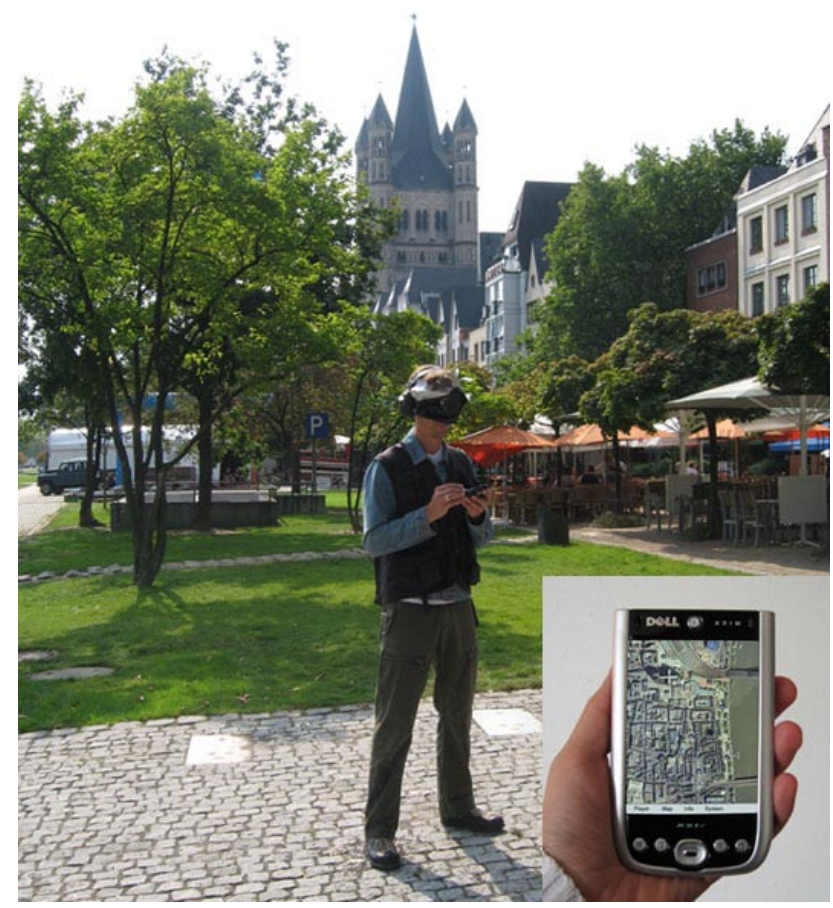

Figure 3 AR system and interactive map.

\subsubsection{Evaluation}

During summer 2007 a large user study was conducted with the objective of testing usability as well as sense of place and presence. The study consisted of 24 participants (16 male, 8 female) from a range of backgrounds including students and members of the public. A combination of approaches were used including a questionnaire, video observation, direct observation and interviews. The questionnaire was based on the MEC spatial presence questionnaire [22] with sections added to reflect the game experience within TimeWarp in particular to reflect whether people felt more present within the real, virtual or blend of the elements. The questionnaire was also extended to include measurements for social presence and place, these were drawn from the place probe [3] and Bailenson social presence questionnaire [2]. The questionnaire data proved to be the least useful within the study due to the confusing terminology and the iterative nature of the system being tested. However it was used to guide interview questions as the interviewer could look for contradictions within answers or to explore any particularly strong feelings which were indicated. From the perspective of video and direct observation we were particularly interested in observing how the users responded to elements of the game, technology and non-game elements - in the case of the latter what if any interaction occurred between them and non-players e.g. passersby in the street. A more thorough discussion of the results can be found in 8 .

\subsection{The Eye of Judgment}

The Eye of Judgment is a collectible trading card game for the Sony PlayStation 3. The game uses Augmented Reality to visualize the characters and effects on the cards. It was developed by Sony Computer Entertainment Japan Studio and was released in October 2007.

\subsubsection{Game play}

In the The Eye of Judgment the player can choose between a computer or real opponent where both players can either be at the same location or connected via the Internet.

In common with typical trading card games, each player has a deck of cards. During each turn players draw new cards and make use of the ones they currently own. The playing field consists of a rectangular grid of nine squares. The player to first conquer five of them wins the game. In order to achieve this goal, a player can either summon monsters onto the playing field attack the opponent's monsters with their own or use different spells for various effects. Each monster has attack, defense and health values. The fights are calculated automatically depending on the stats and are always deterministic. During a fight the map overview (which is normally displayed) switches to an arena view, which contains $3 \mathrm{~d}$ models of the combatants performing their attacks.

\subsubsection{Technology}

The set-up of the game is very simple. A piece of cloth serves as the playing map with the grid drawn on it. On one side of the playing mat the PlayStation 3 camera is placed. The camera is never moved but stays in a fixed position overlooking the whole playing field. 
All trading cards have a small barcode like pattern printed on them. These are called the "Matrix" or "CyberCode" [21]. When the card is hold in front of the camera, the system recognizes it and displays a $3 \mathrm{~d}$ representation of the monster or spell on the screen (desktop AR). Monster cards have to be placed into one of the squares and have to stay there until a monster is defeated. Monsters on the playing field are always rotated by $0^{\circ}, 90^{\circ}, 180^{\circ}$ or $270^{\circ}$ as it is important in which direction the monster is looking.

During the game, the screen displays the playing field which is enhanced by terrain in each square and other graphical effects. The real playing field is never seen on the screen as it is completely overlaid by virtual characters and objects as seen on Figure 4. Aside from monster and spell cards, there are also four function cards that can be used for events such as ending a turn or canceling a move. This way the complete game can be controlled via cards, there is no need for other interaction devices like a controller as soon as the game has started.

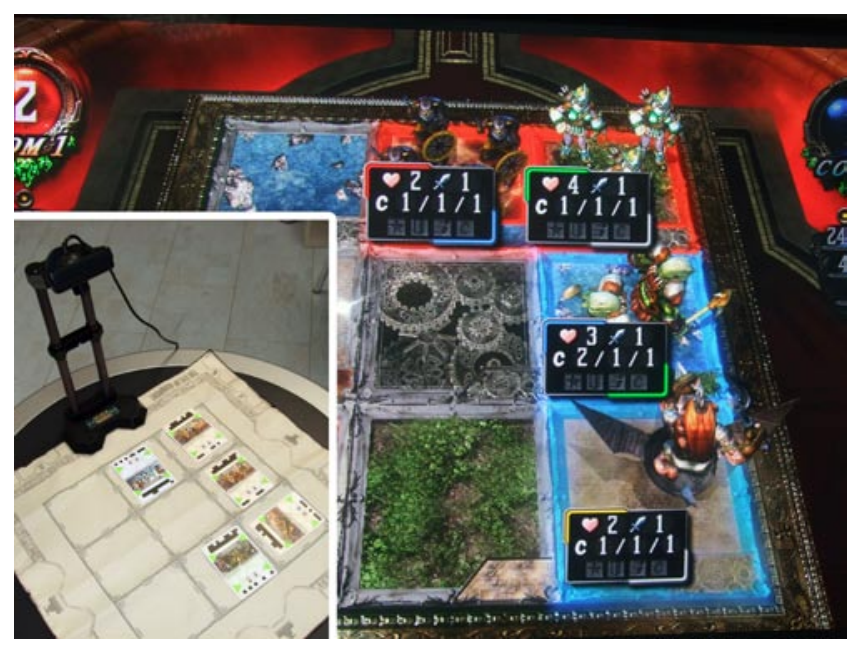

Figure 4. The Eye of Judgment: Playing mat with cards and PlayStation Eye (small) and the augmented view on the screen (big).

\subsubsection{Evaluation}

To evaluate The Eye of Judgment we conducted unassisted user trials. The test persons were a small user group consisted of people with a technical background.

We interviewed the players after they played The Eye of Judgment and discussed the results with the player.

\section{Analysis}

When players encounter AR games for the first time they are typically impressed, enjoy playing them and have ideas for other AR games. However, this observation does not mean that all AR games are "good", rather it is often related to the experience of the new and novel technologies. Most players will never have seen anything similar, and perhaps may only have seen similar technologies in science fiction films or books. It is therefore not surprising that people are typically overwhelmed by the initial experience. However, in order to create stimulating and lasting AR games developers must look beyond these initially responses and place as much effort on the actual game design as for example occurs when developing traditional computer or board games.
Therefore what is needed to create good AR game? And conversely what causes them to fail.

In this section we will analyze the aforementioned games and try to answer the following interconnected questions:

1. What makes AR successful in certain games?

2. What makes AR unsuccessful in other games?

We will use examples from Interference, TimeWarp and The Eye of Judgment to come up with short guidelines that should help when designing AR games in the future. Some of the guidelines are further refinements of those found within prior work [16][12] which were drawn for an extensive user study. It is acknowledged that not all of them are relevant to every augmented reality gamers.

Table 2. Overview of game design guidelines

\begin{tabular}{|c|c|}
\hline $\begin{array}{l}\text { Experiences First, } \\
\text { Technology Second }\end{array}$ & $\begin{array}{l}\text { Design the experience first then } \\
\text { consider the relevant technologies. }\end{array}$ \\
\hline Stick to the theme & $\begin{array}{l}\text { Select technologies which are relevant } \\
\text { to aspects such as time period and } \\
\text { ambience }\end{array}$ \\
\hline Do not stay digital & $\begin{array}{l}\text { Use a combination of real and virtual } \\
\text { elements such as paper maps. }\end{array}$ \\
\hline $\begin{array}{l}\text { Use the Real } \\
\text { Environment }\end{array}$ & $\begin{array}{l}\text { Make use of the real world location, } \\
\text { beyond simply locating virtual elements } \\
\text { in a real space. }\end{array}$ \\
\hline Keep it simple & $\begin{array}{l}\text { Design interaction schemes which are } \\
\text { easy to understand and use }\end{array}$ \\
\hline $\begin{array}{l}\text { Create Sharable } \\
\text { Experiences }\end{array}$ & $\begin{array}{l}\text { Allow other people to take part in the } \\
\text { experience, for example by using tablet } \\
\text { PCs and the magic lens metaphor } \\
\text { rather than a head mounted display. }\end{array}$ \\
\hline $\begin{array}{l}\text { Use Various Social } \\
\text { Elements }\end{array}$ & $\begin{array}{l}\text { Allow players to interact with virtual } \\
\text { characters, other players, non-players } \\
\text { and actors }\end{array}$ \\
\hline Show Reality & $\begin{array}{l}\text { Do not augment spaces so that the } \\
\text { underlying real components are totally } \\
\text { obscured }\end{array}$ \\
\hline $\begin{array}{l}\text { Turn weaknesses } \\
\text { into strengths }\end{array}$ & $\begin{array}{l}\text { Use potential technical problems as } \\
\text { elements within the gaming experience }\end{array}$ \\
\hline Do not just convert & $\begin{array}{l}\text { Do not simply convert a game to } \\
\text { augmented reality }\end{array}$ \\
\hline $\begin{array}{l}\text { Create meaningful } \\
\text { content }\end{array}$ & $\begin{array}{l}\text { The 3d content in the game should add } \\
\text { something interesting to the game. }\end{array}$ \\
\hline $\begin{array}{l}\text { Choose your } \\
\text { tracking wisely }\end{array}$ & $\begin{array}{l}\text { Different tracking methods have } \\
\text { different characteristics that should be } \\
\text { taken into account. }\end{array}$ \\
\hline
\end{tabular}

Experiences First, Technology Second. In all the games earlier one of the main focuses was on the technology, rather than technology which can support the underlying game structure. Based on the experiences in particular with TimeWarp it became clear that while usability and technical elements are critical to success there is a need to place as much emphasis on game design as there is within normal computer and non-computer games. 
Therefore when designing such games care should be taken to avoid pre-selecting which technologies to use, rather the game format should be developed first then appropriate technologies chosen.

Stick to the theme There is often a temptation to select new technologies which are not relevant in the context of the game. For example in Interference the game takes place within a communication network which has to be discovered. Therefore a mobile device such as a UMPC is appropriate as it is technically quite advanced (thus fitting in with the theme) and is also suits the mobile nature of the game. In contrast within TimeWarp if players were asked to collect UMPCs within the Roman Age it would seem inappropriate. Therefore make sure the technology fits the themes of the game.

Do not stay digital. Augmented Reality games do not necessarily have to focus entirely on digital technology. A very good example for this kind of design comes from Interference. Although the players find and analyze the network with the help of the UMPC, they still need to make use of a real paper map in order to orient themselves. This concept can also be extended to include support for real elements such as cups, glasses and other objects within the game, for example using computer vision to detect when users have collected such items. In the case of TimeWarp building in more real elements would have added to the game experience.

Use the Real Environment In street-based games such as TimeWarp where there can be large distances between different mixed reality elements, thus possibly leading to players becoming bored. This problem can be partially avoided by ensuring players make full use of the real space. For example towns and cities often have interesting path structures, which can be used to heighten the senses (e.g. dark streets leading to sinister locations). Other examples may possibly include encouraging players to take a coffee in a real café as part of the game.

Keep it simple. Augmented Reality games such as TimeWarp often use a range of devices and interaction paradigms. However this approach was in stark contrast to both Interference and Eye of Judgment. The latter two examples emphasize the need to focus on simple and clear interaction schemes and avoid situations where trying new technologies becomes the key consideration.

Create Sharable Experiences. Within augmented reality games other players and even non-players may become interested in the content. In Interference the whole group typically gathered around the UMPC when they found a new node and got into dedicated discussions about what they saw, such devices also allow members of the public to gain an insight into the game space something which cannot occur to the same degree within visor based systems.

Use Various Social Elements Some mixed reality experiences such as TimeWarp place a large amount of emphasis on in-game characters being virtual, where as Interference makes use of real life actors. Such a social element can take the form of allowing people to have different roles and thus having to share thoughts on how to complete the challenge, to using actors for certain roles through to including scope for non-game players to be part of the gaming experience. Otherwise there is a risk (as in the case of TimeWarp) that the playing experience becomes somewhat lonely and disconnected from the surrounding environment. Interacting with real persons as part of the game always adds another layer of excitement compared to having only virtual characters. Actors can react much more spontaneously to requests by the players, and can also be used to steer the players into certain directions as done by the three actors in Interference.

Show Reality One of the biggest weaknesses of The Eye of Judgment is the fact that it might not be a "true" Augmented Reality game at all. When playing the game or watching the screen, the real environment is almost completely removed from the users view. A (nicely designed) virtual version of the playing area is all the screen is showing. This is even true when cards come into play, the magical effect is often at times so large that it more or less completely occludes the cards. This leads to the situation where there is almost no need to use augmented reality. .

Turn weaknesses into strengths The technologies used within mixed reality games are often prone to problems, for example poor GPS tracking as experienced during TimeWarp or no mobile phone signal. Where this is the case the game should be designed to support such failures, for example in areas where there is no mobile signal these could be used as hiding places by players. Common problems and the notion of using such seams within seamful design has been discussed by Chalmers [7]. Another method was applied in Interference. As the game was set to be played after dark, the players used flashlights to circumvent the lighting problems with the marker-based tracking. Whenever they now encountered a marker they would use these and while at the same time creating a more intense atmosphere.

Do not just convert It is often tempting to convert existing formats to include augmented or mixed reality, classic examples include The Eye of Judgment, ARQuake and AR Pacman. While the latter two have been well received by those who have taken part, games such as The Eye of Judgment do not map well to augmented reality. After a few turns the initial excitement wears off as the game only tries to be visually more appealing than the originals but does not include genuine engaging game play.

Create meaningful content Augmented Reality adds very interesting visual features to games by bringing virtual 3D content into the real world. This content should be meaningful and really make use of its possibilities. In Interference for example the power lines that lead players to other network nodes could very well have been normal drawings on paper. As mapping out the network is a crucial part of the game play though, it would have not been as engaging with just chalk-drawn lines on the street. A similar example but for much bigger objects comes from TimeWarp. Here the players encountered the life-size medieval model of the Stapelhaus. The player could now wander around and look at it from different directions and distances.

Choose your tracking wisely Realizing and applying new and potentially better tracking methods is always of importance for the development of Augmented Reality applications and games. One should be well aware of the flaws in the chosen method and consider if they distract too much from the actual game play. Using GPS in TimeWarp proved to be a problematic choice for example. The often unreliable and imprecise data lead to Heinzelmännchen seemingly float around and make interaction with them nearly impossible at times. Marker tracking on the other hand as applied in Interference or The Eye of Judgment is much more stable and a simple yet often times effective solution. One big drawback of course is the fact that the markers are visible to the players as well, and so the game can sometimes become a 
"hunt for new markers" and conflict with the suspense of disbelief.

\section{Discussion}

Existing game design methodologies such as the one in Figure 5 by Ermi and Franz Mäyrä [10] define several main areas: audiovisual, fantasy, challenges, physical and cognitive. The work presented in section 4 complements many of these aspects, however they do not focus on generic game design properties such as supporting a sense of winning or combat. Rather they complement the model by instead considering in more detail aspects which are specific to augmented reality games. For example with respect to the fantasy component the guidelines specifically address how to maintain the themes within the game through highlighting the need to select appropriate technologies (e.g. for the given time period). They also specifically explore how to extend the world to include a combination of real and virtual elements, while also exploring the use of real and virtual characters, for example how to improve the social dimension either through allowing shared realties to develop, or through understanding interactions with others. Furthermore they also flag up the danger of using spurious content. The guidelines also extend the nature of the exploration within the game space to the wider real environment, by encouraging designers to select paths in an environment which enhance user experience and encourage exploration.

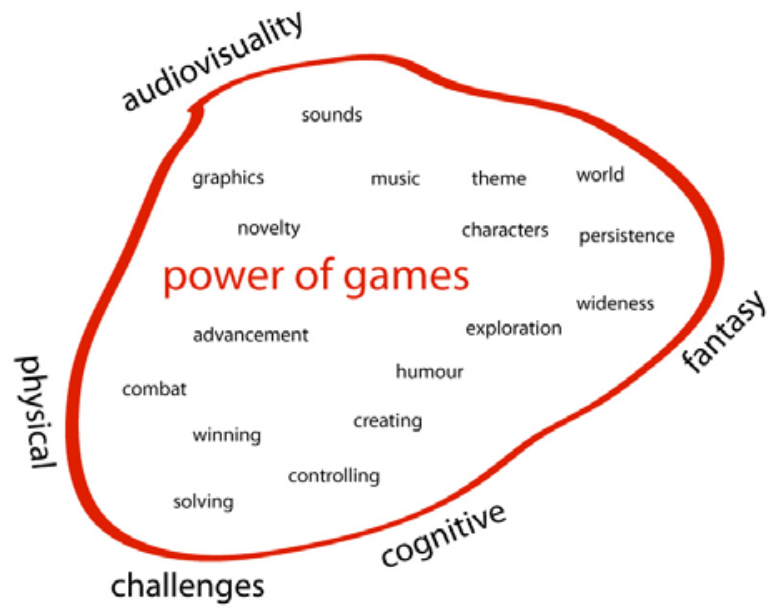

Figure 5. A diagram based on the model developed by Ermi and Mäyra of the aspects necessary for a player to feel immersed within a game.

While the diagram in Figure 5 focused on player immersion within games the field of presence research also played an important role in the development of the guidelines. Although the guidelines do not specifically mention presence, i.e. the feeling of being somewhere (spatial) and/or with others (social) and/or within different time periods (temporal), it is implicit within many of underlying ideas. For example the objective is to ensure that players feel present within the game fantasy world, and with the range of characters. Spatial (and physical presence) is considered from the perspective of how to integrate real and virtual aspects into the gaming experience, either by using real and virtual objects or considering how to make use of real paths and locations. The latter may also have an impact on shaping temporal presence issues. Also considered are aspects relating to social presence, either through the creation of shared realities which players and non-players can experience through to specifically including non-players and actors within the game space. Furthermore classic presence research often places emphasis upon "perceptual illusion of non-mediation" [15] i.e. not being aware of the mediated nature of the experience, this is in part related to the quality of the graphics but also the device interaction paradigms which are adopted, as an ill fitting device would probably result in a break in presence.

\section{Conclusion}

Designing augmented reality games is a challenging task, not least due to the evolving nature of the technology but also from the perspective of how to create lasting, exciting and enjoyable player experiences. In order to explore the issues surrounding the design of mixed reality games we chose to examine three different augmented reality games in order to explore the elements which impacted upon player experience. In two examples the critique is based on first hand experience of the development and evaluation process, where as in the case of The Eye of Judgment this is based on experiences as players. While the games differ in their content and also interaction paradigms they allow us to consider a range of issues from the technical such as augmentations through to how easy it is to adopt existing game paradigms and port them to an augmented reality format. This approach has resulted in a set of high level design guidelines which specifically focus on aspects which are relevant to augmented reality games, in doing so they specifically explore the relationship between real and virtual spaces, real and virtual people as well as certain technical aspects and how to maintain consistent themes. The guidelines were developed to specifically address augmented reality games and while they overlap with some areas of existing game design or presence research they compliment or extend what is already accepted practice, or provide guidance on new aspects which are unique to such experiences. Finally, while they represent a diverse range of themes we acknowledge that further work is required and that they may not be applicable in all contexts.

\section{Acknowledgments}

We thank our colleagues at the Collaborative Virtual and Augmented Environments Department at Fraunhofer FIT for their comments and contributions. We further wish to thank our project partners of the IPerG and IPCity projects for their ideas, cooperation, and support. IPerG (FP6-2003-IST-3-004457) and IPCity (FP6-2004-IST-4-27571) are partially funded by the European Commission as part of the 6th Framework.

\section{REFERENCES}

[1] Azuma, R.: A Survey of Augmented Reality. Presence: Teleoperators and Virtual Environments 6, 4 (August 1997) $355-385$

[2] Bailenson, J.N., Blascovich, J., Beall, A.C., \& Loomis, J.M.. Equilibrium revisited: Mutual gaze and personal space in virtual environments. Presence: Teleoperators and Virtual Environments, 10, 2001, 583-598

[3] Benyon, D. Smyth, M., O’Neill, S., McCall, R. and Carrol, F. The Place Probe: Exploring a Sense of Place in Real and Virtual Environments. Journal of Presence: Tele-operators and Virtual Environments. 15, 6, (2006) 668-687. 
[4] Bichard, John Paul and Waern, Annika: Pervasive Play, Immersion and Story: Designing Interference. In Proceedings of DIMEA2008- to appear

[5] Bier, E., et al., Toolglass and Magic Lenses: The SeeThrough Interface, Proc. ACM Conf. Computer Graphics and Interactive Techniques (Proc. Siggraph), ACM Press, 1993, pp. 73-80.

[6] Broll, W. et al.: Meeting Technology Challenges of Pervasive Augmented Reality Games. Proc. ACM NetGames 06, ACM Press, 2006, article no. 28

[7] Chalmers, M. Seamful Design and Ubicomp Infrastructure. Proceedings of Ubicomp 2003 Workshop at the Crossroads: The Interaction of HCI and Systems Issues in Ubicomp

[8] Cheok, A. et al.: Capture the Flag: Mixed-Reality Social Gaming with Smart Phones. IEEE Pervasive Computing, vol. 5, no. 2, 2006, pp. 62-69.

[9] Cheok, A. et al.: Human Pacman: A Mobile, Wide-Area Entertainment System Based on Physical, Social, and Ubiquitous Computing. Personal Ubiquitous Computing, vol. 8, no. 2, 2004, pp. 71-81

[10] Ermi, L. and Mäyrä, F.: "Fundamental Components of the Gameplay Experience:1 Analysing Immersion" (DiGRA 2005 Conference: Changing Views - Worlds in Play, 2005)

[11] Henrysson, A., Billinghurst, M. and Ollila, M.: Face to Face Collaborative AR on Mobile Phones. Proc. Int. Symposium on Mixed and Augmented Reality (ISMAR 2005), IEEE CS Press, 2005, pp. 80-89

[12] Herbst, I., Braun, A. and Broll, W.: TimeWarp: Interactive Time Travel with a Mobile Mixed Reality Game. In: Proceedings for Mobile HCI 2008 - to appear

[13] Kato, H. and Billinghurst, M. 1999. Marker Tracking and HMD Calibration for a Video-Based Augmented Reality Conferencing System. In Proceedings of the 2nd IEEE and ACM international Workshop on Augmented Reality (October 20 - 21, 1999). IWAR. IEEE Computer Society, Washington, DC, 85.

[14] Lindt, I. et al.: A Report on the Crossmedia Game Epidemic Menace. ACM Computers in Entertainment (CIE), vol. 5, no. 1, 2007, article no. 8

[15] Lombard, M. and Ditton, T(1997) At the heart of it all: The concept of presence. Journal of Computer Mediated Communication, 3 (2).

[16] McCall, R. et al.: The "Where" of Mixed Reality: Some Guidelines for Design. ACM Computer Human Interaction
2008. Workshop on Urban Mixed Realities - Technologies, Theories and Frontiers (Florence, Italy, April 5 - 11, 2008).

[17] Milgram, P., Takemura, H., Utsumi, A. and Kishino, F.: Augmented Reality: A class of displays on the realityvirtuality continuum, SPIE Vol. 2351-34, Proceedings of Telemanipulator and Telepresence Technologies (1994).

[18] Ohlenburg, J., Broll, W. and Braun, A.: Morgan: A Framework for Realizing Interactive Real-Time AR and VR applications. SEARIS, Workshop on Software Engineering and Architecture for Realtime Interactive Systems at IEEE VR 2008.

[19] Piekarski, W. and Thomas, B.: ARQuake: The Outdoor Augmented Reality Gaming System. Comm. ACM, vol. 45, no. 1, 2002, pp.36-38

[20] Reimann, C., Paelke, V. and Stichling, D.: Foot-Based Mobile Interaction with Games. Proc. ACM SIGCHI Int. Conf. Advances Computer Entertainment Technology (ACE 04), vol. 74, ACM Press, 2004, pp. 321-324

[21] Rekimoto, J.: Matrix: A Realtime Object Identification and Registration Method for Augmented Reality. Proc. APCHI, pp. 63-68, 1998.

[22] Vorderer, P., Wirth, W., Gouveia, F. R., Biocca, F., Saari, T., Jäncke, F., Böcking, S.,Schramm, H., Gysbers, A., Hartmann, T., Klimmt, C., Laarni, J., Ravaja, N., Sacau, A., Baumgartner, T., \& Jäncke, P. (2004). MEC Spatial Presence Questionnaire (MEC-SPQ): Short Documentation and Instructions for Application. Report to the European Community, Project Presence: MEC (IST-2001-37661). Online. Available from http://www.ijk.hmthannover.de/presence

[23] Wagner, D. and Schmalstieg, D.: ARToolKitPlus for Pose Tracking on Mobile Devices. Proceedings of 12th Computer Vision Winter Workshop (CVWW'07), February 2007

[24] Wagner, D. et al.: Towards Massively Multi-User Augmented Reality on Handheld Devices. Proc. $3^{\text {rd }}$ Int. Conf. Pervasive Computing, Springer, Berlin/Heidelberg, 2005, pp. 208-219

[25] Wetzel, Richard, Lindt, Irma, Waern, Annika, Jonsson, Staffan. The Magic Lens Box: Simplifying the Development of Mixed Reality. In Proceedings of DIMEA2008 - to appear 